\title{
Investigating Research Hotspots and Publication Trends of Spinal Stenosis: A Bibliometric Analysis during 2000-2018
}

\section{Keda Yang}

First Affiliated Hospital of China Medical University

Lei Pei

First Affiliated Hospital of China Medical University

Kaicheng Wen

First Affiliated Hospital of China Medical University

Siming Zhou

First Affiliated Hospital of China Medical University

Lin Tao ( $\nabla$ taolindr@163.com )

Research article

Keywords: research hotspots, publication trends, spinal stenosis, bibliometric analysis

Posted Date: March 4th, 2020

DOl: https://doi.org/10.21203/rs.3.rs-16061/v1

License: (1) (i) This work is licensed under a Creative Commons Attribution 4.0 International License.

Read Full License

Version of Record: A version of this preprint was published at Frontiers in Medicine on July 20th, 2021.

See the published version at https://doi.org/10.3389/fmed.2021.556022. 


\section{Abstract}

Background: Spinal stenosis is a common elderly disease, present in a variety of forms. High incidence forces researchers to pay more attention and give countermeasures. Our study aimed to conclude the knowledge hierarchy and research anticipation of spinal stenosis according to bibliometric analysis.

Methods: Admitted published papers were obtained from Web of Science Core collection and PubMed database. Bibliometric analysis was conducted by using online analysis software CiteSpace and Bibliographic Item Co-Occurrence Matrix Builder (BICOMB). Exported major MeSH terms were further biclustered with gCLUTO according to co-word analysis. Then the research hotspots and publication trends were identified based on the high-frequency MeSH terms.

Results: 5606 scientific literatures were retrieved about spinal stenosis and the number maintained a roughly increasing trend from 108 in 2000 to 512 in 2018, only declining in 2011. The United States is the country keeping an academic leadership in this field. And the journal SPINE was the most authoritative with total 695 articles and average 12.73 citations. There were 17 major and 18 expanded MeSH terms extracted after bibliometric analysis. Co-word and biclustering analysis revealed seven research hotspots involved in etiology, pathogenesis, clinical manifestation, conservative treatment, operative indication, internal implantation and postoperative complications.

Conclusions: In this study, we revealed the research hotspots in spinal stenosis focusing on the pathogenesis and surgical treatment. Narrowing caused by the pathological change of flavum ligamentum hypertrophy and posterior longitudinal ligament ossification attracts more attention in recent years. Besides, minimally invasive surgery and internal implantation fixation are more valid in clinical. Refining pathological classification, optimizing surgical method and instrument property will be an expectable direction of spinal stenosis.

\section{Background}

Spinal stenosis is a pathological symptom as narrowing of spinal canal and shortening of canal diameters, compression of spinal cord and presence of neurological disturbance. According to vertebral segments, narrowness occurs common in cervical and lumbar spine, rare thoracic appearance. An increasing risk of limb dysfunction, urinary and fecal incontinence exists in elderly with spinal stenosis. By dissecting anatomical structure of spinal canal, bone hyperplasia and fibrous tissue adaptation are the main risks of spinal stenosis[1, 2]. In addition, local inflammatory microenvironment, calcium maladjustment and microbe infection also contribute to disease development[3]. Measure of canal diameter and symptom, auxiliary examined with radiological technology, is the gold of definite diagnosis adopted widely in clinical. Once diagnosed, the treatment means varies with the development of narrowing degree and clinical manifestation. Mild stenosis is usually asymptomatic and hard to detect. There is no requirement to intervene without affecting normal life quality. Non-operation therapy is the first choice including functional exercise, message and traction. The application of drugs, blockade and 
acupuncture remains relatively controversial. But if nervous compression manifestation like pain, numbness and dysfunction of physical activity has seriously troubled the severe stenosis patients[4], the treatment process is usually complicated, especially in the elderly with vascular and neurological claudication. A clinical studies have shown that among patients with lumbar spinal stenosis, with or without degenerative spondylolisthesis, decompression surgery plus fusion surgery did not result in better clinical outcomes at 2 years and 5 years than did decompression surgery alone[5]. However, posterolateral instrumented fusion showed a greater improvement in life quality than decompression alone in another comparation[6]. As discussed above, there are still great controversies in surgical choice and postoperative efficacy. Thus the field of spinal stenosis is expecting to explore.

Bibliometrics, a cross-science of quantitative analysis of all knowledge carriers using mathematical and statistical methods, has been generally recognized to evaluate scientific achievements, treatises and predict research trends in a certain field. It is a comprehensive knowledge system that integrates mathematics, statistics, and bibliography, mainly focusing on quantification. The amount of documents, the number of authors and vocabularies are the measurement objects. This shows the essential feature of bibliometrics is that the output must be "quantity". Quantitative research on literature can be traced back to the beginning of the 20th century. And in 1969, Alan Pritchard named this quantitative analysis method with "bibliometrics". Recently, more and more studies assessed the contribution and trends of publications in various areas. Yao RQ regarded immunosuppression as the hotspots of sepsis by clustering keywords[7]. Ahmad P et al. concluded the high risk factors of Periodontology 2000 by synthesizing the study results of extensive dental institutions[8]. These researches supported the reliability of bibliometrics in evaluating hotspots and directing trends of scientific research.

At present, the speed of knowledge update is constantly accelerating and the experience of previous experts is slightly lagging behind, which brings great challenges to medical workers. Bibliometrics can effectively improve this situation. Before this study, no bibliometric articles are available on spinal stenosis. We adopted the biclustering method of bibliometrics to provide a comprehensive analysis of the current status in spinal stenosis. And our study aim to uncover hotspots and predict trends based on bibliometric analysis.

\section{Methods}

\section{Data source and collection}

All literatures were retrieved in the Web of Science Core Collection (WoS) from January 2000 to December 2018. And the retrieving process had been completed in Dec 30, 2019 to reduce the deviation with constantly updated database. The key indexes of our study are "spinal stenosis" and "English" for language. 5606 literatures were exported and the document types involved in ARTICLE and REVIEW, improving the comprehensive feature of our research. Medical subjects Headings (MeSH) terms express the main idea of a literature, identified for the following co-word associated analysis[9]. For document download, we used the PubMed database, a biomedical information retrieval system developed by 
National Center for Biotechnology Information (NCBI) that was relatively complete in medicine. It was convenient using the MeSH terms directly on PubMed as the keywords with a higher relevance. Our data obtained form Web of Science Core Collection, converted into txt format first, were conducted for quantitative and statistical analysis by CiteSpace, a "citation space" for visualization and the Online Analysis Platform of Literature Metrology (http://bibliometric.com/) for bibliometrics. And the downloaded document, also converted into txt format, were inducted the research generality and evolutionary trend according to co-word and biclustering analysis of $\mathrm{MeSH}$ terms by Bibliographic Item Co-Occurrence Matrix Builder (BICOMB) and gCLUTO. It was necessary to note that three investigators carried out literature screening independently based on the abstracts, conclusions or full articles in our preliminary experiment. The consistency was up to 0.95 . And then we discussed the differences and reached the consensus, which reflected the reliability of our data retrieval.

\section{Data analysis}

We divided the analysis process into three parts from publication content association, high-frequency $\mathrm{MeSH}$ terms filtering and scientific direction prediction.

Citespace is an excellent bibliometric software that can reveal the potential connection between documents visually with the form of scientific kncowledge maps[10]. It is developed based on the WoS data format. Cooperative network analysis, co-occurrence analysis, and co-citation analysis can be performed according to the downloaded data. But data from non-WoS databases need to be converted to WoS data format first. And data dimension of the corresponding database applies to its corresponding scope. We concatenated the retrieved publications with the similarity in journals, publication years, countries, authors and languages by using Citespace, which helped us to select nodes for different focuses conveniently and precisely.

BICOMB were developed by Cui L, et al. from Department of Information Management and Information System (Medical) in China Medical University [11]. Major MeSH terms could be exported to represent the publication core and rank the occurring frequency with Microsoft Excel and GoPubMed. The screening publications were analyzed and checked with a designed model in XML format to extract main information in the beginning. The filter of high-frequency MeSH terms was performed in a binary matrix after preliminary interception through a certain threshold. And the latent biomedical principle could be excavated with association and clustering analysis in terms of the results from binary matrix. Then both the major MeSH terms and their networks were conducted for visualization in graph.

gCLUTO were utilized to carry out biclustering analysis of the major MeSH terms from BICOMB. There are four cluster mothed in gCLUTO: Repeated Bisection, Direct, Agglomerative and Graph, among which we selected Repeated Bisection with highest preciseness. And the classified results of these terms would be extracted in two forms including matrix visualization and mountain visualization[12]. In matrix visualization, colors represented values in the raw data matrix. White equaled to the central value "zero", positive values increased with red deepening and negative value depended on green on the contrary. Rows of matrix held columns with same class. Mountain visualization could make accurate prediction 
with multidimensional scaling. Peak number reflected the clustering number in matrix. Mountain shape provided a rough estimate of data distribution in each cluster. The peak altitude is proportional to the similarity and volume is proportional to the number of containing objects in a cluster. Otherwise the peak color is related to the standard deviation within the cluster, red for low value and blue for high value. And we measured the clustering number constantly to reach the optimal visualized graph to investigate the research hotspots and publication trends of spinal stenosis.

\section{Results}

\section{Quantity of relevant literature}

For literature screening, we set up the keywords as "spinal stenosis" and "language = English". And our retrieval ranged from January $1^{\text {st }}, 2000$ to December $31^{\text {st }}, 2018$. A total of 5147 publications involved in 4651 articles and 496 reviews (Figure 1). It was able to see that the number of publications increased generally from 108 in 2000 to 512 in 2018, only declined in 2011 (Figure 2). And the growth rate was also getting better.

\section{Distribution characteristics of literature}

\section{Most active countries or regions}

Counties or regions distribution of publications in bibliometric analysis contributed to focus on the hotspots of research in spinal stenosis by refining data sources. In our study, we demonstrated the top ten countries proceeding in the field of spinal stenosis according to the publication counts (Figure 3). It was seen that the United States was far ahead of other counties with 1803 literatures followed by Japan (711), China (566) and South Korea (479). There was a noteworthy phenomenon that research level in Northeast Asian countries had gradually increased and surpassed Europe over time. We attributed it to economic development. In addition, the centrality index also reflected the core influence to evaluate research value more exactly. The United States remained a leading position with 0.71 centrality. All of the other countries were in a lower influence, among which Germany was the highest for the centrality equaled to 0.23 (Table 1). It was seen that the cooperative network had been formed between many countries and the level was relatively higher in leading countries (Figure 4).

\section{Top ten active institutions}

We also demonstrated the top ten institutions for spinal stenosis research ordered by the publication number. They were Seoul Natl Univ, Univ Washington, Univ Toronto, Harvard Univ, Yonsei Univ, Kuopio Univ Hosp, Cleveland Clin, Univ Calif San Francisco, Vanderbilt Univ, Johns Hopkins Univ (Table 2). Among them, more than half were from the United States, two institution were from Korea and only one belonged to Finland and Canada in line with the distribution characteristics of countries. Seoul Natl Univ (231), Univ Washington (169), Univ Toronto (155) and Harvard Univ (127) published more than a hundred articles and their average citations were $3.14,20.17,6.14$ and 23.63 respectively. It was clear to see that 
the institution in the United States had relative higher average citation and centrality, which determined the credibility (Table 2). With extensively academic communication among scholars, it was necessary to

develop closer research collaboration between various institutions for the lower level ( 0.015 on density map) (Figure 5).

\section{Distribution characteristics of authors and journals}

There were total 15718 authors involved in the field of spinal stenosis by our retrieval. We paid more attention on ten most active authors including Lee SH, Kim HJ, Manchikanti L, Lee JH and Konno S at all with the order of published counts (Table 3). The top three among them were Lee SH, Kim HJ and Manchikanti $L$ with the number of $73,60,54$. They came from Pusan National University Yangsan Hospital in Korea, Seoul National University Bundang Hospital in Korea and Pain Management Center of Paducah in American. It followed that they contributed most to the development of scientific study, though there was not a large gap with other authors, which also showed the research momentum of spinal stenosis. We draw an associated network based on the integration of cited and co-cited authors by CiteSpace at the same time (Figure 6 and Figure 7). Deyo RA was the co-cited author with the most cocitation(812). Katz JN(659) and Weinstein JN(630), close to each other, ranked second and third place. And the centrality index were $0.18,0.10$ and 0.10 which reflected the credibility and authority of their research (Table 3).

In total, there were 735 journals involved in this field. SPINE and EUROPEAN SPINE JOURNAL are the top two in order of article counts and total number of citations. They were 695, 8847 for SPINE and 426, 2908 for EUROPEAN SPINE JOURNAL. Both of them were Q2 in JCR 2018 standards. The other journals in top ten had been shown in Table 4. On the other hand, average number of citations and impact factor were important evidence to evaluate the influence of journals. PAIN PHYSICIAN(15.91) was the highest in terms of average number of citations, followed by SPINE(12.73) and JOURNAL OF NEUROSURGERYSPINE(7.09). Based on impact factor, JOURNAL OF SPINE JOURNAL was highest of 3.196, second for JOURNAL OF NEUROSURGERY-SPINE(2.998) and third for PAIN PHYSICIAN(2.942). The count of articles published in this ten journals accounted for $42.47 \%$. It was obvious that this ten journals laid a solid foundation for subsequent research on spinal stenosis.

\section{Research hotspots of spinal stenosis based on MeSH clusters}

Through statistical and quantitative analysis of the publications from January 1 in 2000 to December 31 in 2018, 3810 major MeSH and MeSH subheading terms had been concluded with a total frequency of 23785 times. After repeatedly proofreading and balancing, the major MeSH and MeSH subheading terms with occurrence frequency of 56 times and above were regarded as high-frequency ones. Altogether, fiftyseven terms were high in appearance with total 11754 frequency, accounting for $49.42 \%(11754 / 23785)$ (Table 5). The major MeSH terms/subheading MeSH terms, Spinal stenosis/surgery and lumber vertebrae/surgery, appeared more than a thousand even close to two thousand times, which reflected the predilection segment of lumbar vertebrae and treating method of surgery. Biclustering helped us make a classification of these high-frequency major MeSH and MeSH subheading terms, convenient for refining 
main topics of spinal stenosis. As the mothed introduced, the results were visualized in the form of matrix and mountain graph. The color was the core property to reflect the raw matrix value in matrix visualization. The balanced point was white, red color represented positive value and green represented negative value, both of which expressed a positive correlation. In the matrix graph, clusters are separated by black horizontal lines and each row was an individual category. Thus there were seven clusters showing in our matrix (Figure 8). And the row and column tags were the high-frequency major MeSH terms/MeSH subheading terms and the PMIDs of articles. When the matrix were exhibited in dendrogram, the top and left layers would appear to reveal the association with different indexes. In Figure 8, the top tree indicates the relationships among articles, and the left tree indicates the relationships among highfrequency major MeSH terms/MeSH subheading terms. gCLUTO also could rearranged the attitude of rows in initial matrix to integrate the similar rows (Table 6). In our mountain visualization, there were seven peaks existing form 0 to 6 , revealing total seven clusters after biclustering (Figure 9). In the 3D landform, it was visualized the properties of each cluster by comparing the location, volume, altitude and color of corresponding peaks. Location of peaks represented the relative similarity among different clusters with the higher for the closer. Both of the volume and altitude referred to the internal features in clusters. The greater of volume reflected more objects of major MeSH and MeSH subheading terms containing and the altitude demonstrated the internal similarity in direct proportion. Furthermore, the color of peak reflected the deviation degree of dataset, equaling to standard deviation. Cluster5 with a relative red peak referred to lower value and higher with the trend of bluing in our study (Figure 9). As our analysis above, the major MeSH and MeSH subheading terms had been refined into seven categories. These seven clusters are:

Effect of medical imaging in diagnosis of spinal stenosis(Cluster 0 ),

Etiology of spinal stenosis with different pathological symptoms(Cluster 1),

Pathogenesis of spinal stenosis(Cluster 2),

Options of surgical method in particular conditions and adverse effects(Cluster 3),

Role of instrumentations in rehabilitation of patients(Cluster 4),

Surgical indications of spinal stenosis(Cluster 5),

Non-operative therapeutic means of spinal stenosis(Cluster 6).

\section{Discussion}

We have worked out previous literatures about spinal stenosis with retrieval, characterization and clusting. The number of articles published has generally maintained an upward trend with a narrow fluctuation. In 2011, there was an obvious decline but the number rose again in the next year. MeSH terms can reflect the main idea of literatures and combination with a mass of accurate MeSH terms can reveal the hotspots and trends in research fields. Then based on the statistical analysis of BICOMB software, 
"spinal stenosis" have kept the highest occurring frequency all the time, despite declined in individual years with main trend of articles. Finally, software gCLUTO divide these articles into some clusters according to the similarity and co-word analysis of MeSH terms. Through the above process, we can identify the knowledge hierarchy and research anticipation of spinal stenosis.

Cluster0 focuses on the effect of medical imaging in diagnosis. In the final analysis, spinal stenosis is a pathological change caused by morphological changes of the spine column. A fluoroscopy examination is indispensable to determine the site, severity and nature of the lesion. In order to characterize stenosis more precisely, studies had made detail classifications according to different criterion on morpgology. Development of stenosis is closely associated with the annotomic variation including vertebral, soft tissue structure, spinal canal and segmental sigittal diameter. Among them, the common chioce to classify is in terms of the values change of spinal diameter at different segments and sections[13]. Evolutionary tendency of stenosis, whether causing neuropathy and requiring surgical intervention or not, will be speculated according to the numerical standards based on morphologic change. In addition, the norrowing degree in one segment may also suggest corresponding changes and developing trends of other segments[14]. Precise mastery of morphologic imaging change is crucial for selection of therapeutic schedule and prevention of disease progression.

Cluster 1 focuses on the etiology of spinal stenosis with different pathological symptoms. Spinal stenosis is just a generalization of the phenomenon in morphology, norrowing of spinal canal. Various symptoms may be secondary to the physiological structure change and there are great differences in the causes of these concomitant symptoms. A series of neurological symptoms like limb numbness, low back pain and claudication occurs in the patients, most on account of the complication of nerve compression. Cervical stenosis usually resultes in limb paresthesias, dexterity disfunction, imbalance and neck pain[15]. However, development of cervical spondylosis relates to lesion sites, tissue involvement degree, individual differences and classifies into radiculopathy, myelopathy and vertebral artery types instead of simple disc-protrusion or slipped disc[16]. Lumbar stenosis always leades to numbness in the lower limbs, low back pain and even cauda equina compressive symptoms. Accoring to the urgency of incidence, different pathogenic possibilities exist including laminar thickening, facet hyperplasia and vertebral dislocation. Accurate analysis of the etiology is an inevitable requiement for further disposition in all circumstances.

Cluster2 focuses on the pathogenesis of spinal stenosis including pathology structures, segments and sections. And these mainly involve in ligamentum flavum and intervertebral disc, cervical and lumbar spine, sagittal and transverse diameters. Morphological changes of the soft tissue around the spinal canal are the main characteristics of spinal stenosis. Ligamentum flavum forms the dorsal wall of spinal canal, abviously causing norrowness when thickening. As for the reason of thickening, studies have identified the existence of epiligament in ligamentum flavum composed of collagenous fibers while enlargement of epiligament leaded to more collagenous than natural elastic fibers, resulting in the canal taper. Moreover, ligamentum flavum area has been compared with more sensitive measurement parameter than ligament flavum thickness, playing more valuable role[17]. Close to the ventral wall of canal, the herniation of intervertebral disc would narrow the spinal canal. Similar at the ventral wall, 
ossification of posterior longitudinal ligament is also a risk factor. Genetic mutuation causing ectopic osteogenesis of ligament might account for the ossification phenomenon[18]. Up to now, Pavlov's ratio, the ratio of sagittal diameter of spinal canal to that of the corresponding vertebral body, is a reliable diagnostic basis of stenosis. But there is an ignorance of other tissue except bone structure since shown on $\mathrm{X}$ ray. Magnetic Resonance Imaging(MRI), which reveals the pathological change of soft tissues, is an appropriately effective auxiliary to clarify the pathogenesis. In recent studies, researchers had made a comprehensive comparison between the Pavlov's ratio and MRI scan and obtained a moderate correlation[19]. More specific and extensive evaluation of MRI image and traditional diagnostic criteria is conductive to dissect the complex pathogenesis and symptomatic treatment.

Cluster 3 focuses on the options of surgical method in particular conditions and inspection of adverse effect in failure cases. According to the follow-up and postoperative recovery analysis of a large number of past cases, it is clear of the optimal procedure for idiopathic symptom. For instence, anterior decompression with spinal fusion was prior to treat cervical stenosis cuased by posterior longitudinal ligament ossification[20], laminectomy could improve radiculopathy effectively with foraminotomy[21]. Doctors will formulate the most suitable surgical plan after discussion of patients' pathogenesis and evaluation of operation. However, there are still unpredictable postoperative symptoms and complications under with a dequate treatment. Both standard open laminectomy and minimally invasive laminectomy are applied widely to deal with cervical spondylosis by lamina trapping and ligament ossification [22]. But postoperative epidural fibrosis with scar would restrict nerve mobility and increase tense causing nerve injury and pain[23]. Adhesion of dura mater, canal wall and ligamentum flavum also form cerebrospinal fluid leakage if tearing. And intraoperative spinal cord injury even leads to paraplegia. In addition, incomplete decompression, operative area infection and spinal atrophy are all the main factors of failure. For incision, anterior surgury had a higher recovery rate, suigical risk and posterior surgury had more neurological deterioration by contrast. In order to improve recovery and prevent complications, clinicans strive to optimize the operation and contol the soft tissue injury and infection.

Cluster4 focuses on the role of instrumentations in rehabilitation of patients with spinal stenosis after decompression. Seen in previous operative cases, pure spinal fusion or laminectomy for decompression resulted in vertebral instability and increased mobility with a high possibility. Thus, more clinical and fundamental researchers continue to design multiple internal implantations to stabilize injured vertebral structures. The applied effect of each implatation had been adequately inspected. E.H.Kuner evaluated ASIF internal fixator in the operation of spinal fractures. They observed that internal fixation could effectively reduce the remaining encroachment and remodel the spinal canal, which contributed to improve operative effect and reduce operative complication[24]. Since then, various interspinous process decompression(IPD) devices had been tested and applied in clinical. These devices would relieve the load on facet joints, restore the height of intervertebral foramen and maintain the stability of spine. Nevertheless, follow-up survey also revealed the existential risks including spinous process fracture, cerebrospinal fluid leakage and low-back pain[25]. At the moment, the indications for these devices need more preoperative examination, intraoperative observation and postoperative monitoring to determine. And the prevention methods for post-IPD complications need more clinical conclusion as well. 
Cluster 5 focuses on the surgical indications for clinical manifestations. As discussed before, operative intervention was not inevitable and doctors would made optimal plans, in which operation happened only in some conditions. Low back pain, a kind of civilized disease prevalent in modern society, occuring mainly in the fourth and fifth lumbar or fifth lumbar and the first sacral vertebrae, is an important indication. Almost eighty percent adults suffer from the pain with osteomyelitis, fracture and spinal stenosis[26]. Operation will be considered after fall flat with conservative treatment for low back pain uaually caused by disc herniation, spondylolisthesis and degenerative disc disease. Minimizing the surgical trauma is also a critical consideration of the surgeon. So in most cases, minimally invasive interventional approaches are the first choice. Orthopedic minimally invasive techniques such as foraminal, interlaminar and delta mirrors are widely adopted with the superiority of improving function and reducing the side effect from drugs[27]. Meanwhile, surgical intervention executed with appropriate conservative intervention may maximize the therapeutic effect.

Cluster 6 focuses on the non-operative therapeutic means of spinal stenosis. Conservative treatment is favored on account of no collateral damage to organism. As for the judgment of conservative treatment rather than operation, depends on accurate mastery of the clinical examinations including paraspinal tissue morphology, fuctional status and symptoms. There were three main means: oral painkillers, epidural injection and physical therapy, applied to the patients in early stage with moderate symptoms in clinical. Among them, epidural corticosteroid injection had been confirmed to reduce pain, though small and non-sustained[28]. And epidural injection was more cost-effective and safe. The role of physical therapy in relieving pain and restoring function was limited, but necessary exercise therapy contributed to the rehabilitation and complication prevention. Only functional training is less effective than operation in most instances. Nonsteroidal anti-inflammatory drugs(NSAIDs) are most common for drug therapy in clinical. The pharmacological mechanism are reducing nerve stimulation, preventing painful substances secreting and lowering pain threshold. It indicates that NSAIDs cannot fundamentally solve the problem but reduce the perception of pain, or even leading to drug dependence. Therefore, drug therapy is invalid and essential to improve. Overall, non-operative therapy is suitable and prior for mild to moderate patients and available in preoperative preparation and postoperative rehabilitation.

As mentioned above, we have generally described the research status and further trends of spinal stenosis based on last 20 years research. However, there are still reflective research loopholes influencing the analysis results. Firstly, all data are obtained from a single database and not involved in most language countries. A part of literatures with high quality in other databases have been ignored. Collaborative analysis of multiple databases help to improve the universality. Secondly, co-word retrieval based on MeSH terms is limited with occasionality. The number and selection of MeSH terms would make a difference to biclustering results. Thirdly, range of our inflammation retrieval starts from the origination of spinal stenosis researches, maybe a superiority, but just weakening the research trends in recent. Combining more mesurement standards will contribute to capturing research hotspots in the further. 


\section{Conclusion}

Among each stage of spinal stenosis onset, we conclude the hotspots in pathogenesis and therapeutic means. Pathogenesis has always been the focus of disease research, which is helpful to master and judge progression. Ligmentum flavum and posterior longitudinal ligmentum, making up the anteroposterior wall of spinal canal, attacts more attention recently. Pathological changes of ligmentum components including hypertrophy and ossification might alter local morphology, leading to norrowness of spinal canal. Otherwise, publishers care more about the selection of therapeutic means in terms of severity. After long term of follow-up survey and randomized controlled trials, operation combined with proper functional rehabilitation training could maximize the life quality of patients. And the operative principle is more inclined to minimal invasion and internal implantation, which lower the risk of infection and postoperative complications. Further refining pathological classification, optimizing surgical method and instrument property will be an expectable direction of spinal stenosis.

\section{Declarations}

\section{Ethics approval and consent to participate}

Not applicable

\section{Consent for publication}

Not applicable

\section{Availablity of data and material}

The dataset used and analysed during the current study is available from the corresponding author on reasonable request.

\section{Acknowledgement}

This work is supported by National key R \& D projects(2017YFC1104903). We also thank Department of Information Management and Information System (Medical) in China Medical University, providing technological support.

\section{Funding}

No funding was received for this study.

\section{Author Contributions}

Keda Yang and Lei Pei contributed equally to this work 
Conceptualization, LT; Data curation, SMZ; Formal analysis, KDY; Funding acquisition, LP; Investigation, LP; Methodology, SMZ; Project administration, LT; Resources, KCW; Software, KCW; Validation, KDY; Writing - original draft, KDY; Writing - review \& editing, LT.

All authors read and approved the manuscript.

\section{Conflicts of Interest}

The authors declare no conflict of interest.

\section{Abbreviations}

BICOMB: Bibliographic Item Co-Occurrence Matrix Builder

MeSH: Medical Subject Headings

WoS: Web of Science Core Collection

NCBI: National Center for Biotechnology Information

JCR: Journal Citation Reports

MRI: Magnetic Resonance Imaging

ASIF: anterior subcutaneous internal fixator

IPD: interspinous process decompression

NSAIDs: Nonsteroidal anti-inflammatory drugs

\section{References}

1. Chen X, Feng S, Guan H, Yu Z, Cui L, Wang Y, Xu S, Yuan X: [Radiological characteristics and clinical manifestation of isolated lumbar foraminal stenosis]. Zhonghua wai ke za zhi [Chinese journal of surgery] 2015, 53(8):584-588.

2. Du JP, Fan Y, Hao DJ: Rare Hereditary Abnormal Bone Hyperplasia and Ossification of the Yellow Ligament Complicated by Thoracic Spinal Stenosis. World neurosurgery 2018, 115:99-100.

3. Melancia JL, Francisco AF, Antunes JL: Spinal stenosis. Handbook of clinical neurology 2014, 119:541-549.

4. Ogink PT, Teunis T, van Wulfften Palthe O, Sepucha K, Bono CM, Schwab JH, Cha TD: Variation in costs among surgeons for lumbar spinal stenosis. The spine journal : official journal of the North American Spine Society 2018, 18(9):1584-1591. 
5. Forsth P, Olafsson G, Carlsson T, Frost A, Borgstrom F, Fritzell P, Ohagen P, Michaelsson K, Sanden B: A Randomized, Controlled Trial of Fusion Surgery for Lumbar Spinal Stenosis. The New England journal of medicine 2016, 374(15):1413-1423.

6. Ghogawala Z, Dziura J, Butler WE, Dai F, Terrin N, Magge SN, Coumans JV, Harrington JF, AminHanjani S, Schwartz JS et al: Laminectomy plus Fusion versus Laminectomy Alone for Lumbar Spondylolisthesis. The New England journal of medicine 2016, 374(15):1424-1434.

7. Yao RQ, Ren C, Wang JN, Wu GS, Zhu XM, Xia ZF, Yao YM: Publication Trends of Research on Sepsis and Host Immune Response during 1999-2019: A 20-year Bibliometric Analysis. International journal of biological sciences 2020, 16(1):27-37.

8. Ahmad P, Asif JA, Alam MK, Slots J: A bibliometric analysis of Periodontology 2000. Periodontology 2000 2020, 82(1):286-297.

9. Yang S, Kim CY, Hwang S, Kim E, Kim H, Shim H, Lee I: COEXPEDIA: exploring biomedical hypotheses via co-expressions associated with medical subject headings (MeSH). Nucleic acids research 2017, 45(D1):D389-d396.

10. Synnestvedt MB, Chen C, Holmes JH: CiteSpace Il: visualization and knowledge discovery in bibliographic databases. AMIA Annual Symposium proceedings AMIA Symposium 2005:724-728.

11. Lei C: Development of a Text Mining System Based on the Co-occurrence of Bibliographic Items in Literature Databases. New Technology of Library \& Information Service 2008.

12. Wei WJ, Shi B, Guan X, Ma JY, Wang YC, Liu J: Mapping theme trends and knowledge structures for human neural stem cells: a quantitative and co-word biclustering analysis for the 2013-2018 period. Neural regeneration research 2019, 14(10):1823-1832.

13. Miyazaki M, Takita C, Yoshiiwa T, Itonaga I, Tsumura H: Morphological analysis of the cervical pedicles, lateral masses, and laminae in developmental canal stenosis. Spine 2010, 35(24):E13811385.

14. van Eck CF, Spina lii NT, Lee JY: A novel MRI classification system for congenital functional lumbar spinal stenosis predicts the risk for tandem cervical spinal stenosis. European spine journal : official publication of the European Spine Society, the European Spinal Deformity Society, and the European Section of the Cervical Spine Research Society 2017, 26(2):368-373.

15. Rowe PC, Marden CL, Heinlein S, Edwards CC, 2nd: Improvement of severe myalgic encephalomyelitis/chronic fatigue syndrome symptoms following surgical treatment of cervical spinal stenosis. Journal of translational medicine 2018, 16(1):21.

16. Hohmann D, Kugelgen B, Liebig K: [Chronic spondylogenic cervical myelopathy. Pathogenesis, prognosis, therapy]. Der Orthopade 1985, 14(2):101-111.

17. Kim YU, Park JY, Kim DH, Karm MH, Lee JY, Yoo JI, Chon SW, Suh JH: The Role of the Ligamentum Flavum Area as a Morphological Parameter of Lumbar Central Spinal Stenosis. Pain physician 2017, 20(3):E419-e424.

18. Wang P, Liu X, Kong C, Liu X, Teng Z, Ma Y, Yong L, Liang C, He G, Lu S: Potential role of the IL17RC gene in the thoracic ossification of the posterior longitudinal ligament. International journal of 
molecular medicine 2019, 43(5):2005-2014.

19. Prasad SS, O'Malley M, Caplan M, Shackleford IM, Pydisetty RK: MRI measurements of the cervical spine and their correlation to Pavlov's ratio. Spine 2003, 28(12):1263-1268.

20. Masaki Y, Yamazaki M, Okawa A, Aramomi M, Hashimoto M, Koda M, Mochizuki M, Moriya H: An analysis of factors causing poor surgical outcome in patients with cervical myelopathy due to ossification of the posterior longitudinal ligament: anterior decompression with spinal fusion versus laminoplasty. Journal of spinal disorders \& techniques 2007, 20(1):7-13.

21. Snow RB, Weiner H: Cervical laminectomy and foraminotomy as surgical treatment of cervical spondylosis: a follow-up study with analysis of failures. Journal of spinal disorders 1993, 6(3):245250; discussion 250-241.

22. Alimi M, Hofstetter CP, Pyo SY, Paulo D, Hartl R: Minimally invasive laminectomy for lumbar spinal stenosis in patients with and without preoperative spondylolisthesis: clinical outcome and reoperation rates. Journal of neurosurgery Spine 2015, 22(4):339-352.

23. Lin CL, Jou IM, Wu CY, Kuo YR, Yang SC, Lee JS, Tu YK, Chen SC, Huang YH: Topically Applied CrossLinked Hyaluronan Attenuates the Formation of Spinal Epidural Fibrosis in a Swine Model of Laminectomy. Scientific reports 2019, 9(1):14613.

24. Kuner EH, Schlickewei W, Kuner A, Hauser U: Restoration of the spinal canal by the internal fixator and remodeling. European spine journal : official publication of the European Spine Society, the European Spinal Deformity Society, and the European Section of the Cervical Spine Research Society 1997, 6(6):417-422.

25. Gazzeri R, Galarza M, Neroni M, Fiore C, Faiola A, Puzzilli F, Callovini G, Alfieri A: Failure rates and complications of interspinous process decompression devices: a European multicenter study. Neurosurgical focus 2015, 39(4):E14.

26. van den Berg R, Jongbloed EM, de Schepper EIT, Bierma-Zeinstra SMA, Koes BW, Luijsterburg PAJ: The association between pro-inflammatory biomarkers and nonspecific low back pain: a systematic review. The spine journal : official journal of the North American Spine Society 2018, 18(11):21402151.

27. Urits I, Burshtein A, Sharma M, Testa L, Gold PA, Orhurhu V, Viswanath O, Jones MR, Sidransky MA, Spektor B et al: Low Back Pain, a Comprehensive Review: Pathophysiology, Diagnosis, and Treatment. Current pain and headache reports 2019, 23(3):23.

28. Chou R, Hashimoto R, Friedly J, Fu R, Bougatsos C, Dana T, Sullivan SD, Jarvik J: Epidural Corticosteroid Injections for Radiculopathy and Spinal Stenosis: A Systematic Review and Metaanalysis. Annals of internal medicine 2015, 163(5):373-381.

\section{Tables}

Table 1 The top 10 countries/regions: article counts and centrality of publications in spinal stenosis research. 


\begin{tabular}{|c|c|c|c|}
\hline Rank & Country/region & Article counts & Centrality index \\
\hline 1 & USA & 1803 & $\mathbf{0 . 7 1}$ \\
\hline 2 & JAPAN & 711 & $\mathbf{0 . 0 3}$ \\
\hline 3 & CHINA & $\mathbf{5 6 6}$ & $\mathbf{0 . 0 1}$ \\
\hline $\mathbf{4}$ & SOUTH KOREA & $\mathbf{4 7 9}$ & $\mathbf{0 . 0 1}$ \\
\hline $\mathbf{5}$ & GERMANY & 293 & $\mathbf{0 . 2 3}$ \\
\hline $\mathbf{6}$ & UK & $\mathbf{2 4 8}$ & $\mathbf{0 . 1 4}$ \\
\hline $\mathbf{7}$ & CANADA & 218 & $\mathbf{0 . 0 8}$ \\
\hline $\mathbf{9}$ & SWITZERLAND & $\mathbf{1 7 3}$ & $\mathbf{0 . 0 4}$ \\
\hline 10 & TURKEY & 169 & $\mathbf{0 . 0 1}$ \\
\hline
\end{tabular}

Table 2 The top 10 institutions for most publications in spinal stenosis research.

\begin{tabular}{|c|c|c|c|c|c|c|c|c|c|}
\hline Rank & Institution & $\begin{array}{l}\text { Article } \\
\text { counts }\end{array}$ & $\begin{array}{c}\text { Total number of } \\
\text { citations }\end{array}$ & $\begin{array}{c}\text { Average number } \\
\text { of citations }\end{array}$ & $\begin{array}{c}\text { Total number of first } \\
\text { authors }\end{array}$ & $\begin{array}{l}\text { Total number of } \\
\text { first author } \\
\text { citations }\end{array}$ & $\begin{array}{l}\text { Average number of } \\
\text { first author citations }\end{array}$ & $\begin{array}{l}\text { Centrality } \\
\text { index }\end{array}$ & Country \\
\hline 1 & Seoul Natl Univ & 231 & 725 & 3.14 & 64 & 259 & 4.05 & 0.04 & Korea \\
\hline 2 & Univ Washington & 169 & 3408 & 20.17 & 33 & 369 & 11.18 & 0.1 & US \\
\hline 3 & Univ Toronto & 155 & 994 & 6.41 & 31 & 157 & 5.06 & 0.12 & Canada \\
\hline 4 & Harvard Univ & 127 & 3001 & 23.63 & 34 & 606 & 17.82 & 0.15 & US \\
\hline 5 & Yonsei Univ & 97 & 363 & 3.74 & 41 & 157 & 3.83 & 0.03 & Korea \\
\hline 6 & Kuopio Univ Hosp & 95 & 1543 & 16.24 & 23 & 194 & 8.43 & & Finland \\
\hline 7 & Cleveland Clin & 88 & 386 & 4.39 & 25 & 99 & 3.96 & 0.02 & US \\
\hline 8 & $\begin{array}{l}\text { Univ Calif San } \\
\text { Francisco }\end{array}$ & 87 & 1344 & 15.45 & 35 & 128 & 3.66 & 0.1 & US \\
\hline 9 & Vanderbilt Univ & 86 & 1815 & 21.1 & 32 & 161 & 5.03 & 0.03 & US \\
\hline 10 & Johns Hopkins Univ & 84 & 194 & 2.31 & 34 & 62 & 1.82 & 0.02 & US \\
\hline
\end{tabular}

Table 3 The top 10 most productive authors and co-cited authors contributing to publications in spinal stenosis research.

\begin{tabular}{|c|c|c|c|c|c|c|c|c|c|c|}
\hline Article counts & $\begin{array}{c}\text { Total number } \\
\text { of citations }\end{array}$ & $\begin{array}{c}\text { Average } \\
\text { number of } \\
\text { citations }\end{array}$ & $\begin{array}{c}\text { First author } \\
\text { counts }\end{array}$ & $\begin{array}{l}\text { First author } \\
\text { citation counts }\end{array}$ & $\begin{array}{c}\text { Average first } \\
\text { author citation } \\
\text { counts }\end{array}$ & $\begin{array}{c}\text { Corresponding } \\
\text { author }\end{array}$ & $\begin{array}{r}\text { Corresponding } \\
\text { g author citation } \\
\text { counts }\end{array}$ & $\begin{array}{c}\text { Co-cited } \\
\text { author }\end{array}$ & Citation counts & $\begin{array}{c}\text { Centrality } \\
\text { index }\end{array}$ \\
\hline 73 & 360 & 4.93 & 10 & 37 & 3.7 & 10 & 88 & Deyo RA & 812 & 0.18 \\
\hline 60 & 269 & 4.48 & 28 & 126 & 4.5 & 3 & 27 & Katz JN & 659 & 0.1 \\
\hline 54 & 1610 & 29.81 & 50 & 1520 & 30.4 & 50 & 1520 & Weinstein JN & 630 & 0.1 \\
\hline 46 & 163 & 3.54 & 18 & 103 & 5.72 & 16 & 58 & Atlas SJ & 448 & 0.09 \\
\hline 45 & 294 & 6.53 & 3 & 93 & 31 & 3 & 93 & Boden SD & 397 & 0.08 \\
\hline 39 & 317 & 8.13 & 0 & 0 & 0 & 0 & 0 & Amundsen T & 383 & 0.1 \\
\hline 37 & 1290 & 34.86 & 6 & 113 & 18.83 & 9 & 117 & Herkowitz HN & 347 & 0.16 \\
\hline 36 & 1431 & 39.75 & 4 & 778 & 194.5 & 7 & 852 & Verbiest $\mathbf{H}$ & 309 & 0.08 \\
\hline 36 & 176 & 4.89 & 5 & 61 & 12.2 & 7 & 46 & Turner JA & 289 & 0.07 \\
\hline 34 & 234 & 6.88 & 7 & 50 & 7.14 & 11 & 53 & Epstein NE & 288 & 0.08 \\
\hline
\end{tabular}

Table 4 The top 10 journals contributing to publish articles in spinal stenosis research.

\begin{tabular}{|c|c|c|c|c|c|c|c|c|c|c|}
\hline Article counts & $\begin{array}{c}\text { Total number } \\
\text { of citations }\end{array}$ & $\begin{array}{c}\text { Average } \\
\text { number of } \\
\text { citations }\end{array}$ & $\begin{array}{l}\text { First author } \\
\text { counts }\end{array}$ & $\begin{array}{l}\text { First author } \\
\text { citation counts }\end{array}$ & $\begin{array}{c}\text { Average first } \\
\text { author citation } \\
\text { counts }\end{array}$ & $\begin{array}{c}\text { Corresponding } \\
\text { author }\end{array}$ & $\begin{array}{l}\text { Corresponding } \\
\text { author citation } \\
\text { counts }\end{array}$ & $\begin{array}{l}\text { Co-cited } \\
\text { author }\end{array}$ & Citation counts & $\begin{array}{c}\text { Centrality } \\
\text { index }\end{array}$ \\
\hline 73 & 360 & 4.93 & 10 & 37 & 3.7 & 10 & 88 & Deyo RA & 812 & 0.18 \\
\hline 60 & 269 & 4.48 & 28 & 126 & 4.5 & 3 & 27 & Katz JN & 659 & 0.1 \\
\hline 54 & 1610 & 29.81 & 50 & 1520 & 30.4 & 50 & 1520 & Weinstein JN & 630 & 0.1 \\
\hline 46 & 163 & 3.54 & 18 & 103 & 5.72 & 16 & 58 & Atlas SJ & 448 & 0.09 \\
\hline 45 & 294 & 6.53 & 3 & 93 & 31 & 3 & 93 & Boden SD & 397 & 0.08 \\
\hline 39 & 317 & 8.13 & 0 & 0 & 0 & 0 & 0 & Amundsen $\mathrm{T}$ & 383 & 0.1 \\
\hline 37 & 1290 & 34.86 & 6 & 113 & 18.83 & 9 & 117 & Herkowitz HN & 347 & 0.16 \\
\hline 36 & 1431 & 39.75 & 4 & 778 & 194.5 & 7 & 852 & Verbiest $\mathbf{H}$ & 309 & 0.08 \\
\hline 36 & 176 & 4.89 & 5 & 61 & 12.2 & 7 & 46 & Turner JA & 289 & 0.07 \\
\hline 34 & 234 & 6.88 & 7 & 50 & 7.14 & 11 & 53 & Epstein NE & 288 & 0.08 \\
\hline
\end{tabular}




\begin{tabular}{|c|c|c|c|c|c|c|c|c|c|c|}
\hline Artide counts & $\begin{array}{c}\text { Total number" } \\
\text { of citations }\end{array}$ & $\begin{array}{l}\text { Average } \\
\text { number of } \\
\text { ititations }\end{array}$ & $\begin{array}{c}\text { Cirst author } \\
\text { counts }\end{array}$ & $\begin{array}{l}\text { lirst author" } \\
\text { citation counts }\end{array}$ & $\begin{array}{l}\text { Average firs } \\
\text { author citatio } \\
\text { counts }\end{array}$ & $\begin{array}{l}\text { (Correspondint } \\
\text { author }\end{array}$ & $\begin{array}{l}\text { Corresponding } \\
\text { ing author ritation } \\
\text { counts }\end{array}$ & $\begin{array}{l}\text { II Co-vited } \\
\text { author }\end{array}$ & (itation coullts & $\begin{array}{l}\text { Centrality } \\
\text { sinder }\end{array}$ \\
\hline 73 & 360 & 4.93 & 10 & 31 & 3.7 & 11 & 88 & Deyo RA & 812 & 0.18 \\
\hline 60 & 260 & 4.48 & 28 & 126 & 4.5 & 3 & 11 & Katald & 659) & 0.1 \\
\hline 54 & 1610 & 29.81 & 50 & 1520 & 30.4 & 50 & 1520 & Weinstein NN & $1 \quad 630$ & 0.1 \\
\hline 46 & 163 & 3,54 & 18 & 103 & 5.12 & 16 & 58 & Attas SJ & 448 & 0.19 \\
\hline 45 & 24 & 6.53 & 3 & 93 & 31 & 3 & 93 & Boden SD & 397 & 0.18 \\
\hline 3) & 311 & 8.13 & 0 & 0 & 0 & 0 & 0 & Amundsen I & 383 & 0.1 \\
\hline 37 & 1290 & 34.86 & 6 & 113 & 18.83 & 9 & 111 & Herkowitz HN & II 347 & 0.16 \\
\hline 36 & 1431 & 39,15 & 4 & 778 & 194.5 & 1 & 834 & Verbiest H & 3010 & 0.18 \\
\hline 36 & 176 & 4.89 & $j$ & ${ }_{11}$ & 12.2 & 1 & 46 & Turner JA & 289 & V.ror \\
\hline 34 & 234 & 6.88 & 1 & 50 & 9.14 & 11 & 33 & Enstein NE & 188 & ono \\
\hline
\end{tabular}

Table 5 High-frequency major MeSH terms from the involved publications on spinal stenosis $(n=23785)$.

Table 6 High-frequency major MeSH a terms-source articles matrix (localized).

\begin{tabular}{|c|c|c|c|c|c|c|c|c|c|c|}
\hline Article counts & $\begin{array}{l}\text { Total number } \\
\text { of citations }\end{array}$ & $\begin{array}{c}\text { Average } \\
\text { number of } \\
\text { citations }\end{array}$ & $\begin{array}{l}\text { First author } \\
\text { counts }\end{array}$ & $\begin{array}{l}\text { First author } \\
\text { citation counts }\end{array}$ & $\begin{array}{c}\text { Average first } \\
\text { author citation } \\
\text { counts }\end{array}$ & $\begin{array}{c}\text { Corresponding } \\
\text { author }\end{array}$ & $\begin{array}{l}\text { Corresponding } \\
\text { author citation } \\
\text { counts }\end{array}$ & $\begin{array}{l}\text { Co-cited } \\
\text { author }\end{array}$ & Citation counts & $\begin{array}{c}\text { Centrality } \\
\text { index }\end{array}$ \\
\hline 73 & 360 & 4.93 & 10 & 37 & 3.7 & 10 & 88 & Deyo RA & 812 & 0.18 \\
\hline 60 & 269 & 4.48 & 28 & 126 & 4.5 & 3 & 27 & Katz JN & 659 & 0.1 \\
\hline 54 & 1610 & 29.81 & 50 & 1520 & 30.4 & 50 & 1520 & Weinstein JN & 630 & 0.1 \\
\hline 46 & 163 & 3.54 & 18 & 103 & 5.72 & 16 & 58 & Atlas SJ & 448 & 0.09 \\
\hline 45 & 294 & 6.53 & 3 & 93 & 31 & 3 & 93 & Boden SD & 397 & 0.08 \\
\hline 39 & 317 & 8.13 & 0 & 0 & 0 & 0 & 0 & Amundsen $\mathrm{T}$ & 383 & 0.1 \\
\hline 37 & 1290 & 34.86 & 6 & 113 & 18.83 & 9 & 117 & Herkowitz HN & 347 & 0.16 \\
\hline 36 & 1431 & 39.75 & 4 & 778 & 194.5 & 7 & 852 & Verbiest $\mathbf{H}$ & 309 & 0.08 \\
\hline 36 & 176 & 4.89 & 5 & 61 & 12.2 & 7 & 46 & Turner JA & 289 & 0.07 \\
\hline 34 & 234 & 6.88 & 7 & 50 & 7.14 & 11 & 53 & Epstein NE & 288 & 0.08 \\
\hline
\end{tabular}

\section{Figures}




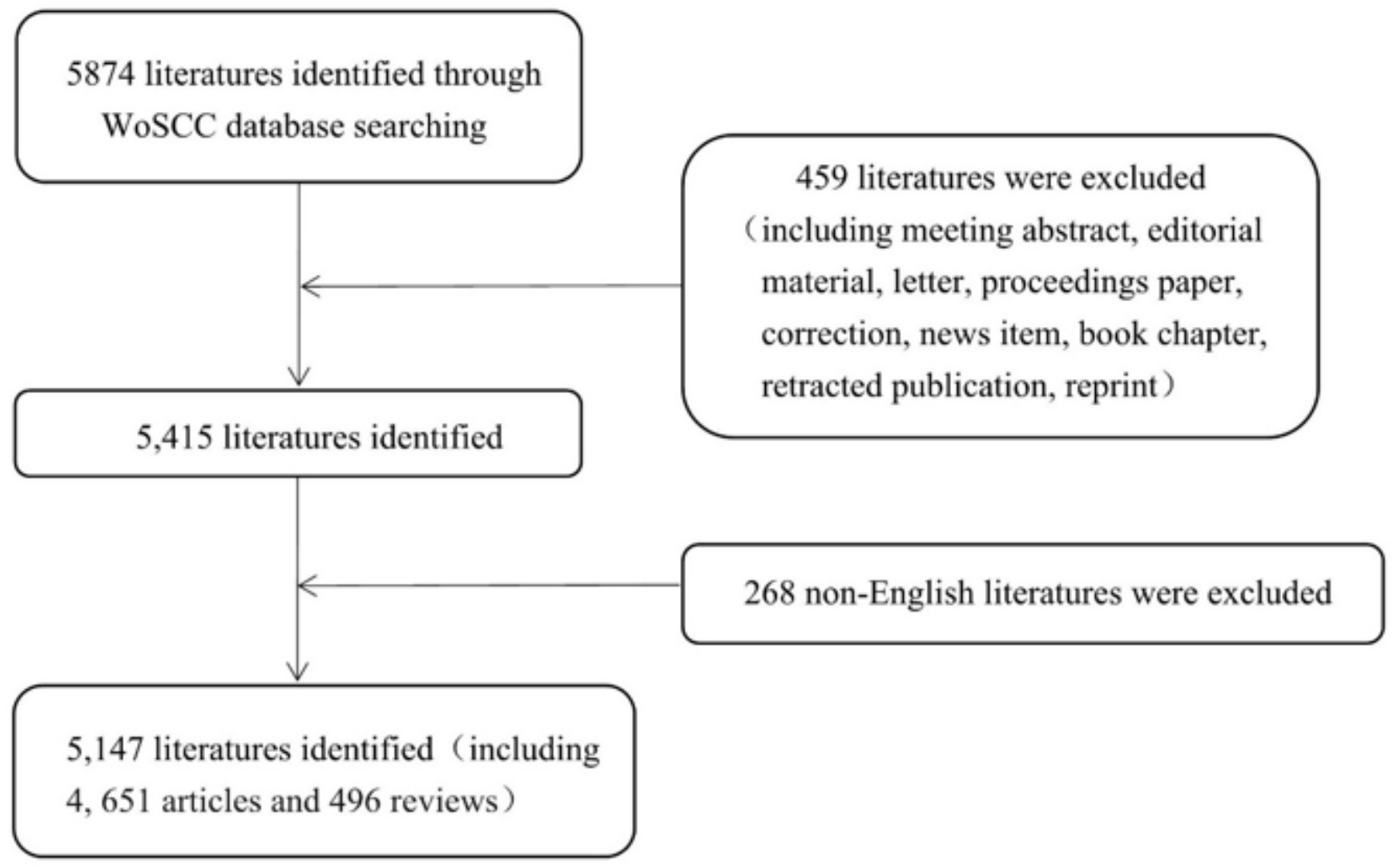

\section{Figure 1}

Flow chart of literature filtering involved in this study.

\section{Growth Trend}

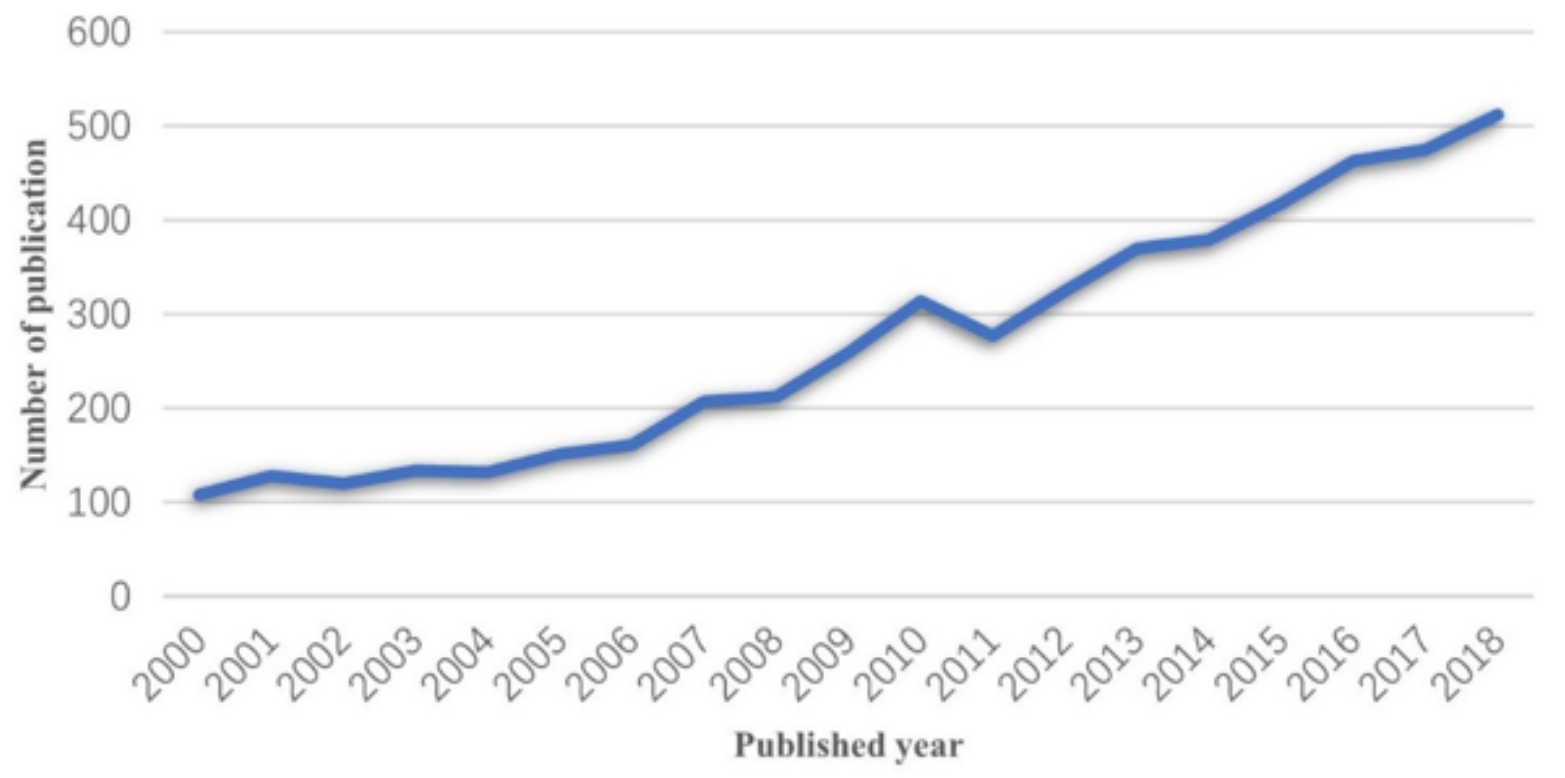


Figure 2

Quantity of relevant literature. The number of annual publications in spinal stenosis from 2000 to 2018 .

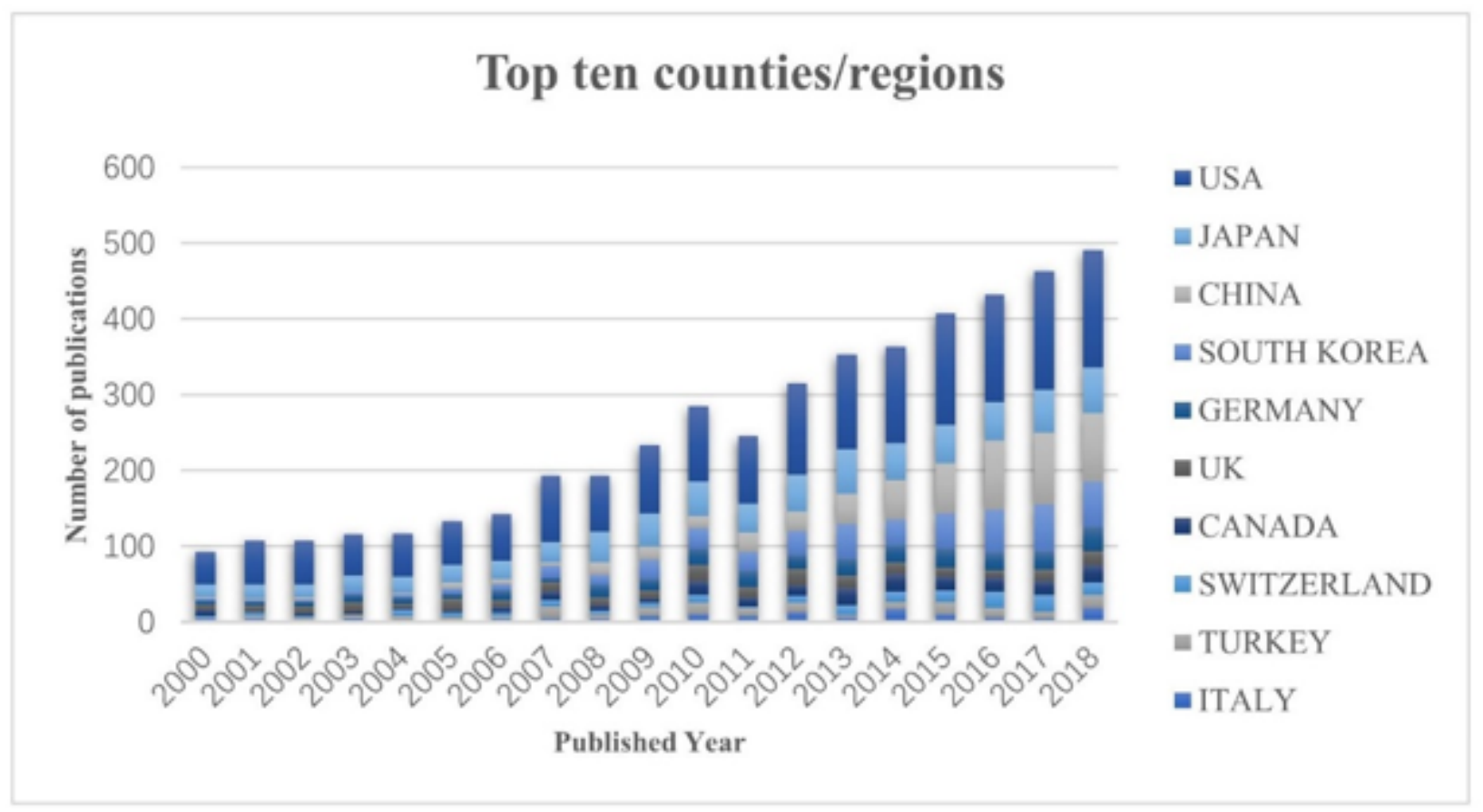

\section{Figure 3}

Quantity of relevant literature. The development of the top 10 countries/regions in spinal stenosis from 2000 to 2018. 


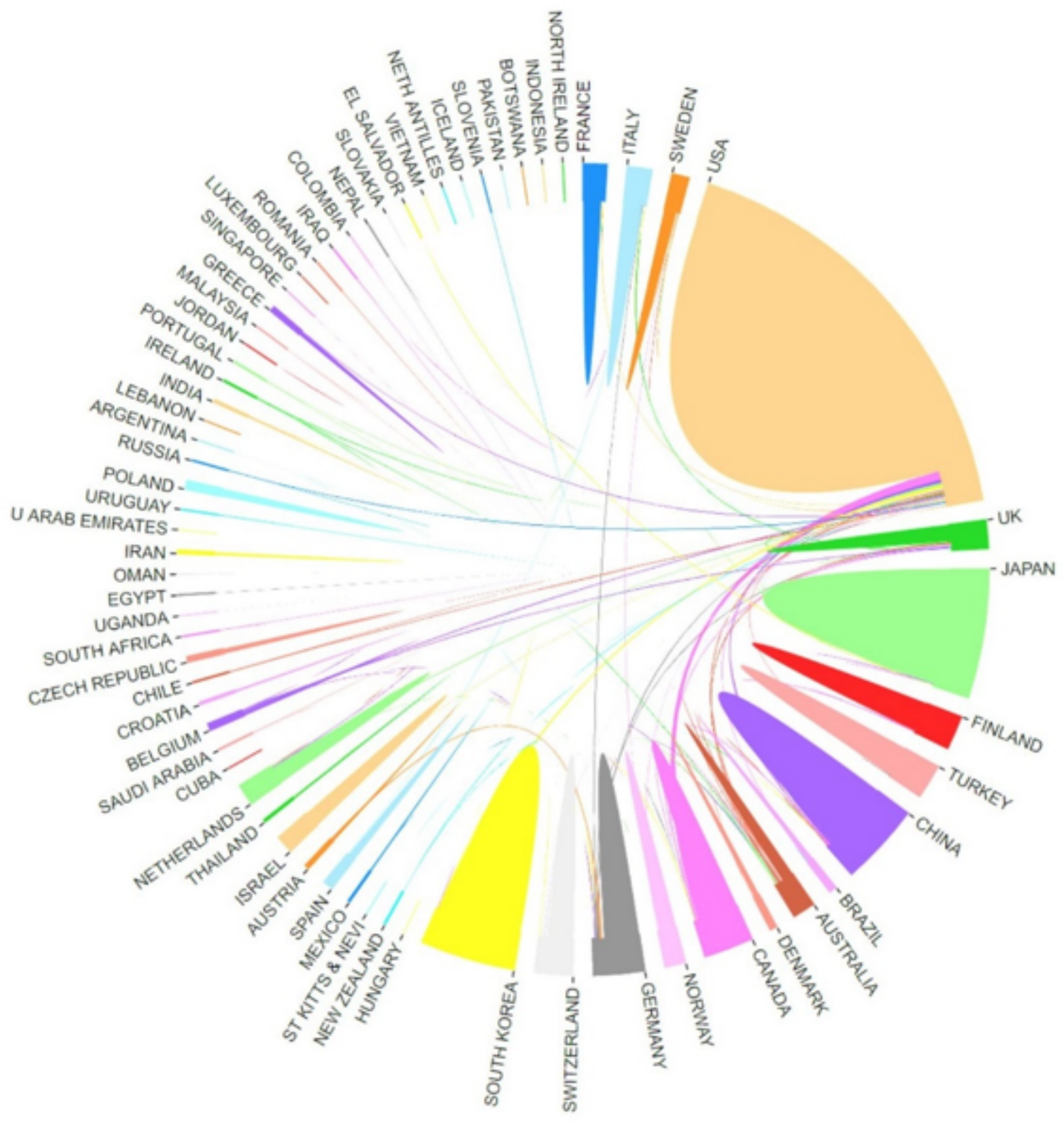

Figure 4

Most active countries or regions. The cooperation of countries/regions involved in spinal stenosis research. 


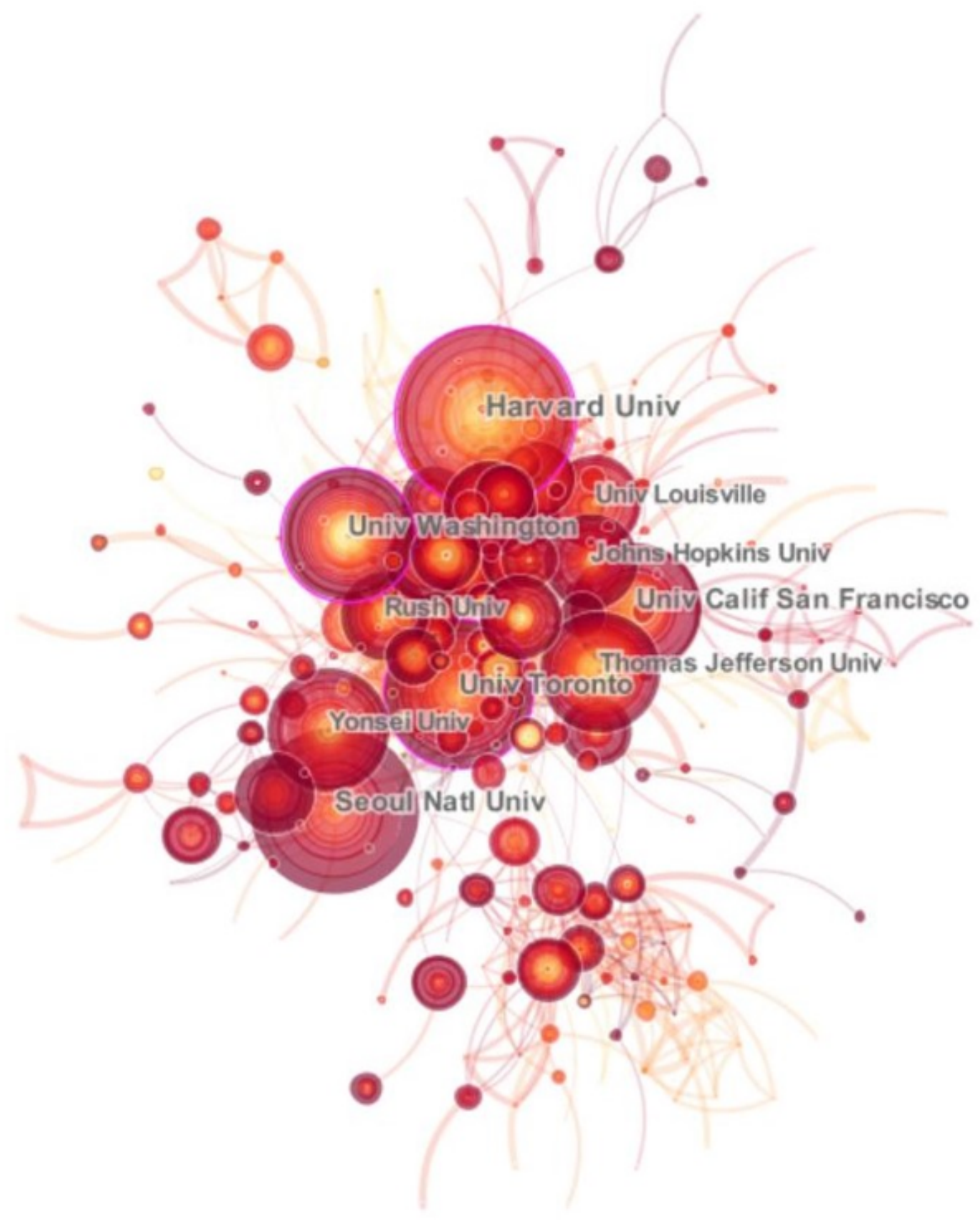

Figure 5

Top ten active institutions. The collaborative network of institutions involved in spinal stenosis research. 


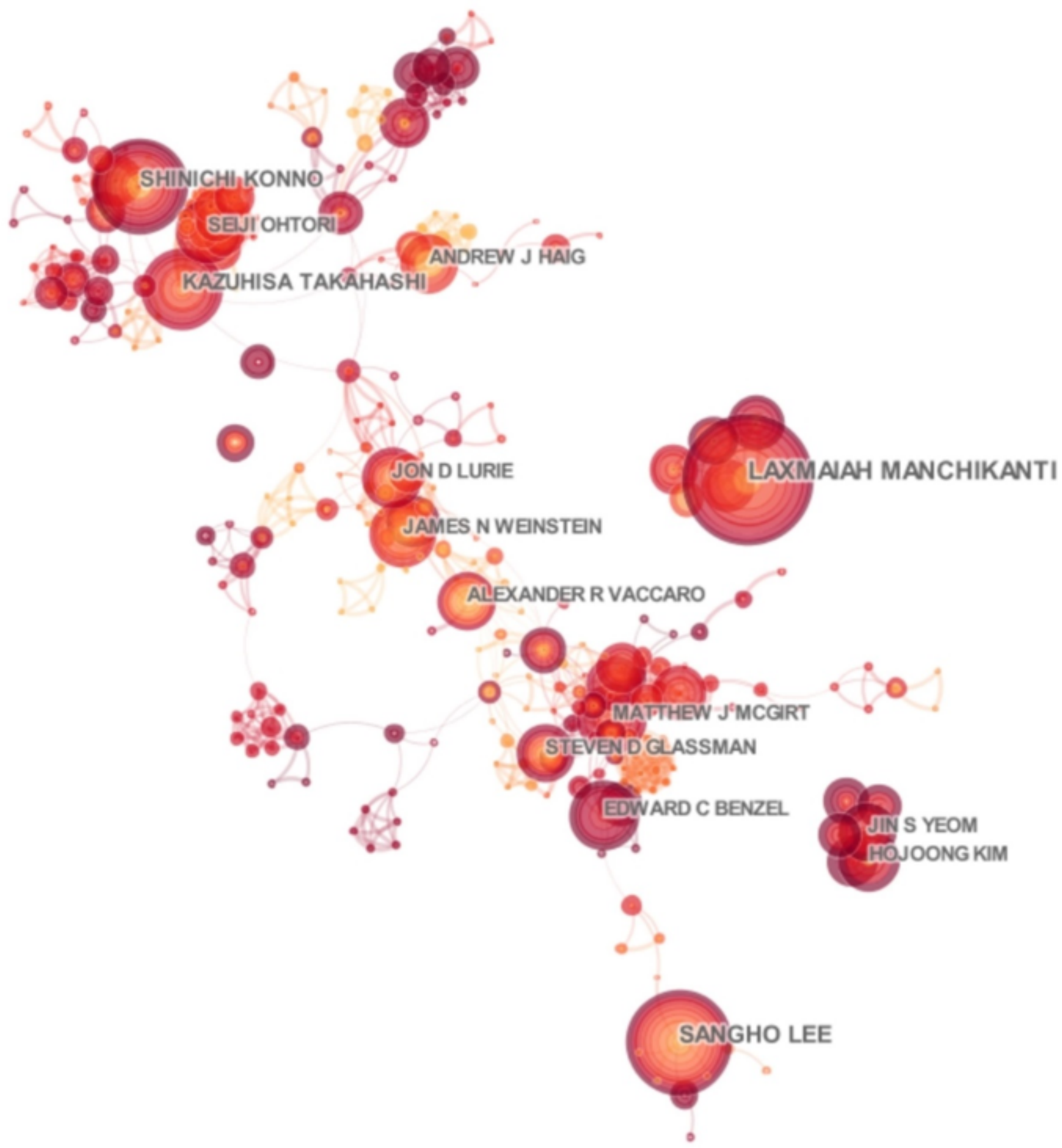

Figure 6

Distribution characteristics of authors. The associated network of productive authors. 


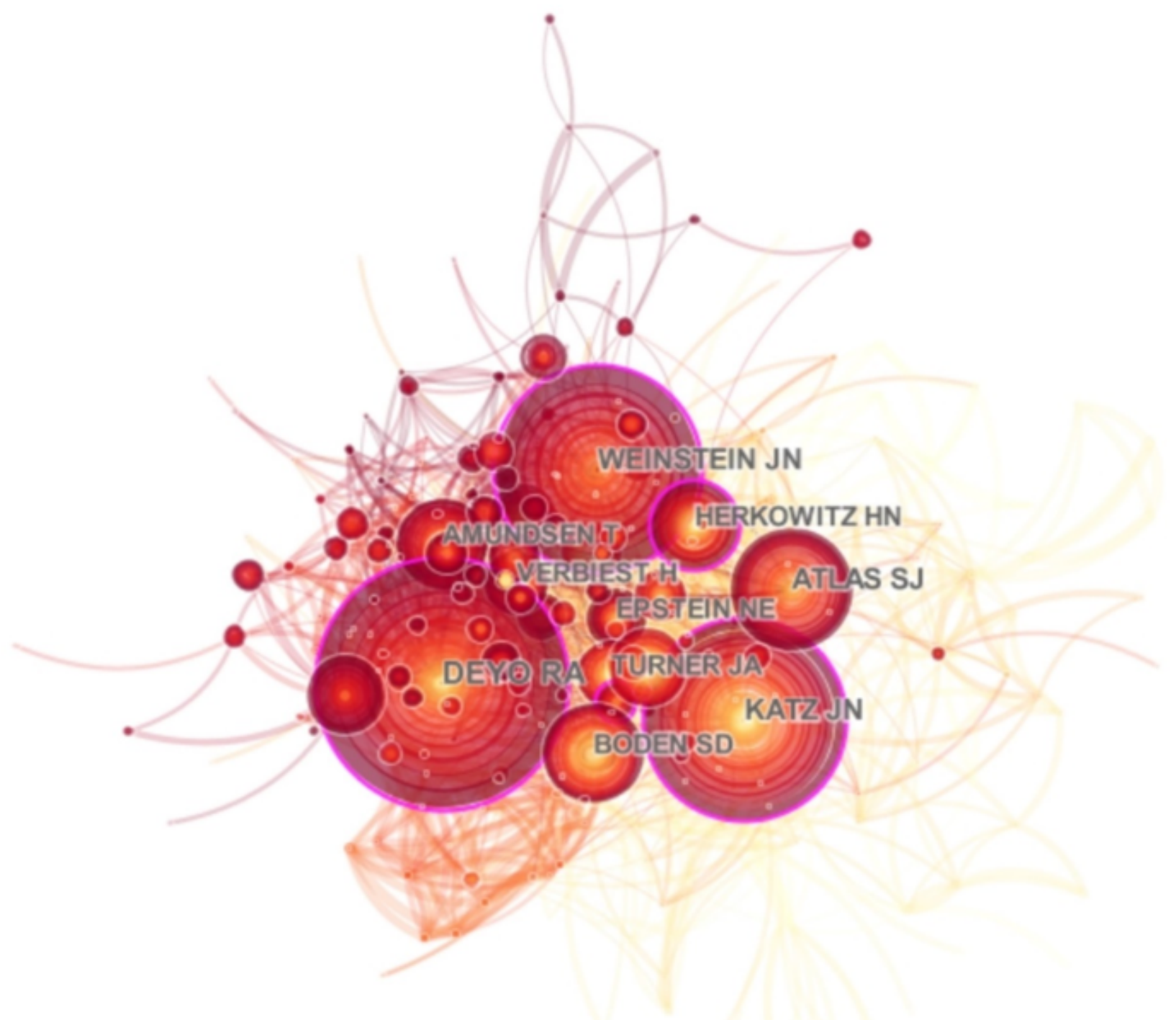

Figure 7

Distribution characteristics of authors. The associated network of co-cited authors. 

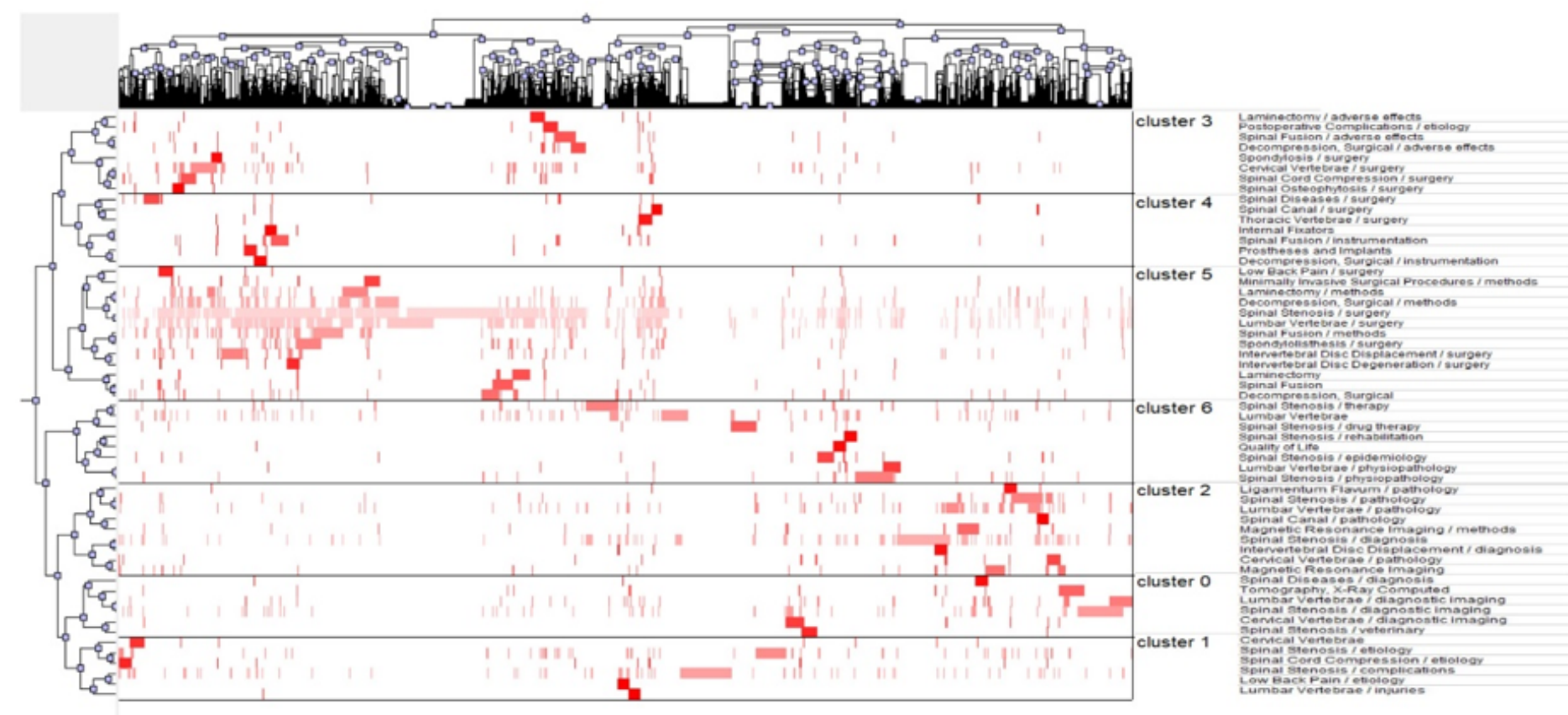

\section{Figure 8}

Matrix visualization of biclustering of high-frequency major MeSH terms and PMIDs of articles on spinal stenosis.

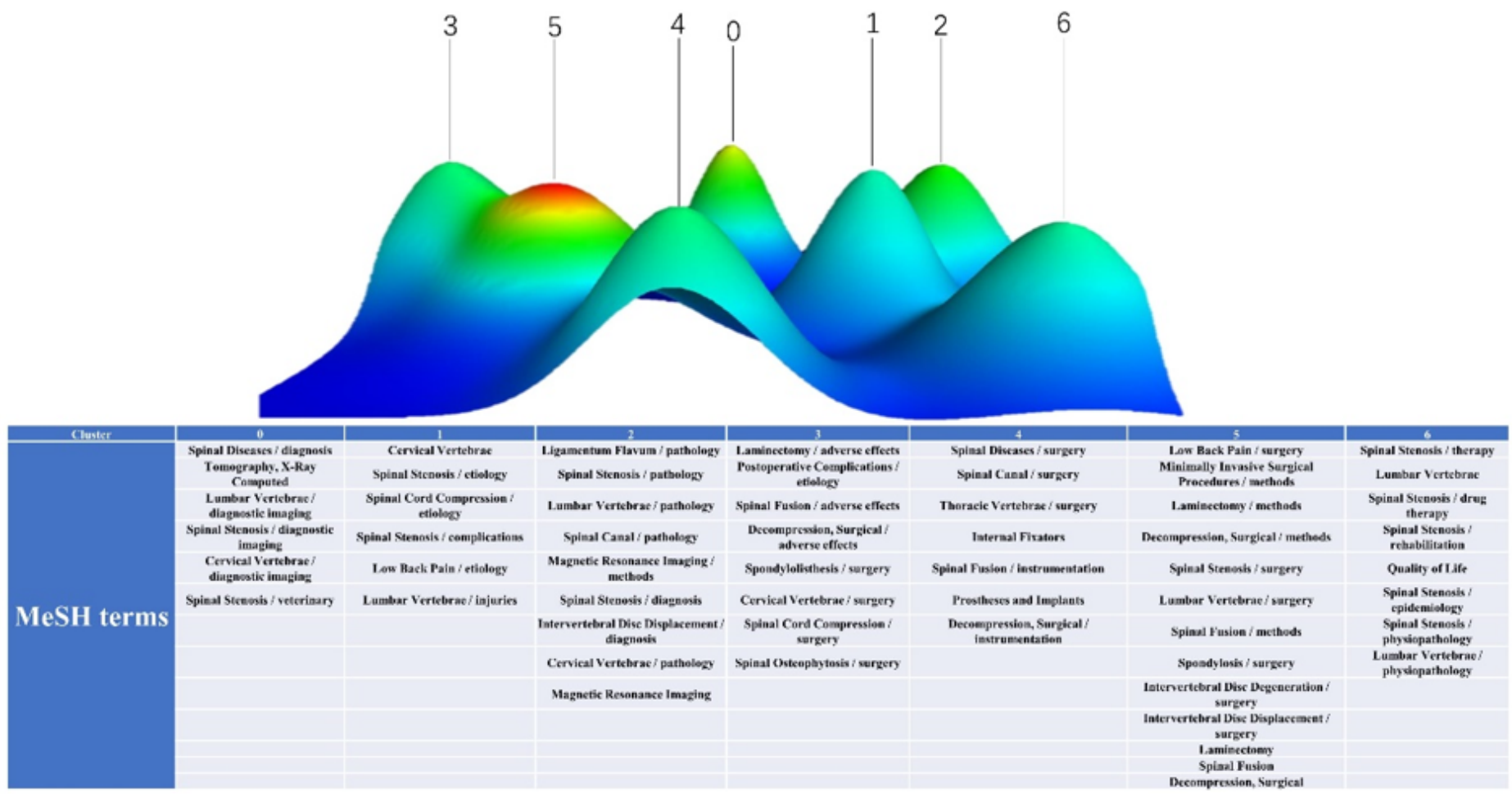

Figure 9 
Mountain visualization of biclustering of high-frequency major MeSH terms and articles on spinal stenosis. 